
\title{
$\begin{array}{ll}\text { Research Square } & \text { They should not be considered conclusive, used to inform clinical practice, } \\ \text { or referenced by the media as validated information. }\end{array}$
}

\section{Promoting Respectful Maternity Care using a Behavioral Design Approach in Zambia: Results from a Mixed-Methods Evaluation}

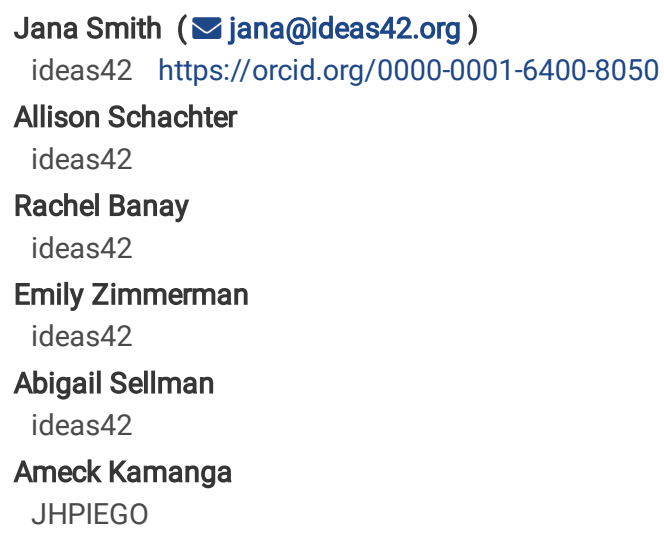




\section{Abstract}

Background: Respectful maternity care (RMC) has been elevated in the global discourse, however, instances of disrespect and abuse remain prevalent. While several studies have highlighted promising approaches to promote RMC, this body of literature is still limited and few approaches have been scaled outside the initial study sites. Building on formative research conducted through a behavioral science lens, we sought to develop and test evidence-based, low-cost solutions to promote RMC which would be well-positioned for scale-up. Our study highlights the effectiveness of the solution package on provider provision of better care and client satisfaction, as well as intermediary outcomes and behavioral mechanisms.

Methods: A quasi-experimental evaluation, informed by the behavioral design approach, was completed to test the effectiveness of a 5-component solution package in Chipata, Zambia. Quantitative surveys were collected from health facility providers and postpartum clients at baseline and endline in intervention and comparison facilities. Additional qualitative interviews were conducted with health facility providers and postpartum clients at endline. We also conducted interviews with health facility in-charges and observed labor and delivery practices at intervention facilities over the course of implementation.

Results: Evidence suggested that at endline, clients at implementation facilities were less likely to experience disrespect and abuse compared to clients at comparison facilities $(B=-0.15 p=.01)$. Clients at intervention facilities were more likely to request pain management compared to clients at comparison facilities $(B=.33, p=.003)$. The solutions were simple for providers to implement and were easily integrated into existing services by providers during labor and delivery. Providers at intervention facilities also described the pain management toolkit as helpful in expanding the types of pain management techniques used during labor.

Conclusions: The results of this small-scale study act as a proof of concept, demonstrating that the behavioral design approach can lead to solutions that show potential for impact. In other settings where providers face similar barriers to providing RMC, an adaptation of this solution package might lead to similarly positive results. Given the global scale of disrespectful care, these low-cost solutions hold promise for improving the quality of care women receive during labor and delivery.

\section{Background}

Respectful maternity care (RMC) has been elevated in the global discourse, however, instances of disrespect and abuse remain prevalent: a 2019 fourcountry (Ghana, Guinea, Myanmar and Nigeria) WHO study found that 35 percent of women surveyed had experienced "physical or verbal abuse, or stigma or discrimination" during childbirth (1). While several studies have highlighted promising approaches to promote RMC, this body of literature is still limited and few approaches have been scaled outside the initial study sites (2-4).

Formative research conducted through a behavioral science lens in Chipata, Zambia demonstrated that disrespectful care was prevalent and providers experienced several behavioral barriers to provision of respectful maternity care (5). Building on these findings, we developed and tested evidencebased, low-cost solutions to promote RMC and that have the potential to be scaled. This study describes an approach for developing evidence-based interventions and shares findings on the impact of this solution package on final outcomes as well as intermediary outcomes and behavioral mechanisms. The aim of this research is to further the understanding of approaches to address disrespect and abuse during labor and delivery and to improve women's experience of care.

\section{Methods}

\section{Intervention and Evaluation Design}

We employed Datta \& Mullainathan's (6) behavioral design approach to systematically design the interventions. This approach has been used to address a wide range of public health challenges in low- and middle-income countries including gender-based violence, reproductive health, and neglected tropical diseases (7-9). First, we defined the problem and then conducted qualitative, formative research to identify the behavioral barriers inhibiting the provision of RMC. The behavioral barriers and their accompanying contextual features identified in this formative research are described in Table 1 and are published elsewhere (5). 
Table 1

Mapping of Contextual Features to Interventions

\begin{tabular}{|c|c|c|c|c|c|}
\hline Behavioral Barrier & Drivers that underlie behavioral barriers & $\begin{array}{l}\text { Pain } \\
\text { Management } \\
\text { Toolkit }\end{array}$ & $\begin{array}{l}\text { Provider- } \\
\text { Client } \\
\text { Promise }\end{array}$ & $\begin{array}{l}\text { Feedback } \\
\text { Box }\end{array}$ & $\begin{array}{l}\text { Reflection } \\
\text { Workshop }\end{array}$ \\
\hline \multirow[t]{4}{*}{$\begin{array}{l}\text { Providers believe they are } \\
\text { already doing everything } \\
\text { they are supposed to do }\end{array}$} & $\begin{array}{l}\text { Training, supervision and feedback is focused on clinical } \\
\text { treatment and health risks and does not address respectful } \\
\text { care }\end{array}$ & $\mathrm{X}$ & & $\mathrm{X}$ & $\mathrm{X}$ \\
\hline & $\begin{array}{l}\text { There are clinical algorithms and guidelines, including } \\
\text { visual cues in the facility, but nothing which provides clear } \\
\text { guidelines for how to give good care }\end{array}$ & $\mathrm{x}$ & $x$ & & \\
\hline & $\begin{array}{l}\text { Pain is seen as a natural birth experience-the provider had } \\
\text { a painful delivery, has attended many painful deliveries, and } \\
\text { the bible says that labor is painful }\end{array}$ & $\mathrm{x}$ & $\mathrm{x}$ & & $\mathrm{x}$ \\
\hline & $\begin{array}{l}\text { Provider has attended many deliveries and developed a } \\
\text { "feel" for how care is provided }\end{array}$ & $x$ & & & $x$ \\
\hline \multirow[t]{2}{*}{$\begin{array}{l}\text { Harsh treatment is } \\
\text { considered normal }\end{array}$} & $\begin{array}{l}\text { Provider experienced violence as a child as a form of } \\
\text { discipline }\end{array}$ & & & & $x$ \\
\hline & $\begin{array}{l}\text { Training and clinical experience of provider reinforces that } \\
\text { clients need rigid, forcefully delivered commands and } \\
\text { interventions }\end{array}$ & & $x$ & & $x$ \\
\hline \multirow{3}{*}{$\begin{array}{l}\text { Providers believe they do not } \\
\text { need to provide respectful } \\
\text { care }\end{array}$} & $\begin{array}{l}\text { There are no serious consequences to providers who } \\
\text { engage in disrespectful or abusive behavior }\end{array}$ & & & $\mathrm{x}$ & $x$ \\
\hline & $\begin{array}{l}\text { Client clothing or appearance makes them seem low- } \\
\text { income, or they are considered to be a community member } \\
\text { of lower status }\end{array}$ & & $x$ & $\mathrm{x}$ & $x$ \\
\hline & $\begin{array}{l}\text { Provider has never interacted with the client before delivery } \\
\text { and the client is behaving erratically or not following } \\
\text { instructions }\end{array}$ & $x$ & $x$ & & $x$ \\
\hline \multirow{2}{*}{$\begin{array}{l}\text { Providers perceive that the } \\
\text { costs of respectful care } \\
\text { outweigh the gains }\end{array}$} & $\begin{array}{l}\text { Maternal or infant death results in an audit, placing an } \\
\text { emphasis on clinical practices }\end{array}$ & & & $x$ & $x$ \\
\hline & $\begin{array}{l}\text { Providers do not receive salient information or feedback on } \\
\text { the impact of respectful or disrespectful care on health } \\
\text { outcomes }\end{array}$ & $x$ & & & $x$ \\
\hline $\begin{array}{l}\text { Providers believe that } \\
\text { disrespectful care will assist } \\
\text { their clinical objectives }\end{array}$ & $\begin{array}{l}\text { Client does not follow provider instructions in part due to } \\
\text { lack of rapport, extreme pain and fatigue }\end{array}$ & $x$ & $x$ & & $x$ \\
\hline
\end{tabular}

Using insights derived from the formative research, we then developed a solution package using an iterative co-design process with a range of different stakeholders including the District Health Office of Chipata, the local team from our implementing project partner (SM360+), the research team, clinicians (midwives and their supervisors), and women in labor. The co-design process resulted in the design of a solution package consisting of five components described below.

1. BETTER Pain Management Toolkit: The toolkit was intended to incorporate pain management into routine client care. BETTER stands for Breathe, Encourage, Turn, Think, and Rub. The toolkit includes (1) Pain management technique posters to cue both providers and clients to pain management support (2) Pain management manual, (3) massage balls, and a (4) pain management partograph guide.

2. Feedback Box: The feedback box was intended to empower clients to share feedback and provide the means to regularly assess clinic performance. Women were provided with a token upon discharge from the maternity ward and instructed to insert the token into the slot that best reflected the service they received.

3. Provider-Client Promise: The promise sought to clarify and set expectations for behavior of both providers and clients and reassure clients of the treatment they should receive. Providers promised to encourage and support the client, explain why procedures are needed, help to manage pain and not to yell, scold or slap the client. Clients promised not to push until the providers says so, to allow the provider to examine her, to lie on her side when asked and to let the provider know when she was in pain or had a question. The document was read aloud by providers upon admission to the labor ward and was signed by both provider and client.

4. Fresh Start Funds: The funds were intended to generate a sense of "fresh start" for the staff and a sense of agency in changing the experience of care. Facilities were provided with a small fund, which they used to make small changes to the labor ward to improve the non-clinical client experience.

5. Reflection Workshop: The workshop encouraged providers to reflect on client care, build an intention to change care as a facility, and introduce solutions. 
To inform our approach, we also constructed a theory of change (see Fig. 1) of our solution package drawing from our formative research and other published literature

We evaluated the effectiveness of these interventions implementing a quasi-experimental study design.

\section{Study Setting}

Chipata District, Eastern Province, Zambia was identified as the area of implementation. As an urban area, Chipata has the largest population, and highest population density in Eastern Province (10) as well as a number of health facilities with relatively high client volumes. Chipata was also identified as a priority district for our local partner organization.

We conducted an evaluation of the solution package from September through December 2019. The evaluation was conducted in 10 urban and rural public facilities. Facilities were eligible for inclusion if our local partner, SM360+, operated programs there. The solution package was implemented in five facilities, and five additional facilities were identified as comparisons and received no solution package. Each comparison facility was matched to a comparable intervention facility on the basis of the following criteria: average number of monthly deliveries, size of staff, size of catchment population, and distance from the district health office (city center). All facilities served clients of similar socio-economic status.

Table 2

Demographics of Intervention and Comparison Facilities

\begin{tabular}{|c|c|c|}
\hline & Intervention & Comparison \\
\hline Average size of population served & 13,791 & 10,761 \\
\hline Average number of staff members that attend to pregnant women (includes nurses, midwives and clinical officers) & 5 & 3 \\
\hline Average number of deliveries per month & 52 & 31 \\
\hline Average distance from the District Health Office & $34.6 \mathrm{Km}$ & $33 \mathrm{Km}$ \\
\hline
\end{tabular}

\section{Study participants}

To understand the effect and experience implementing the RMC solution package, we undertook a quasi-experimental study using quantitative survey data from health facility providers and postpartum clients as well as qualitative interview data with providers and clients. Quantitative surveys were administered at study baseline, prior to the start of the intervention, and quantitative surveys and qualitative interviews were completed at endline, following just over 2 months of implementation.

Clients were eligible to participate if they delivered at the health facilities within 4-8 weeks of the time of survey administration, delivered a live birth and were 18 years or older. All facility providers who support labor and delivery services at the facility were invited to participate in the survey. Different clients were surveyed at baseline and endline. While all facility staff who supported labor and delivery services at the health facility were invited to participate in the survey at baseline and endline, not all providers who participated in the baseline survey were available at endline. Therefore, we measured changes in outcomes at the facility level rather than at the individual level. We also conducted interviews with health facility in-charges and observed labor and delivery practices at intervention facilities (11).

\section{Materials and processes}

Data was collected by a research consultant and a member of the local partner's monitoring and evaluation team. In Chipata, the district lead from our local partner organization facilitated introductions to staff at all ten health facilities. We obtained permission from facility supervisors to speak with and observe their staff, and conducted an informed written consent process with each participant before beginning the interview. We obtained ethical approval from a U.S.-based as well as a local Zambian Institutional Review Board. Participants received 60 kwacha (approximately \$4 USD) as compensation for their time. Surveys and interviews with clients as well as facility observations were conducted by female data collector while the provider interviews were conducted by both male and female data collectors. Surveys were conducted with only one data collector present. The questionnaires used in the study were developed for the purpose of this study though validated measures were adapted and included such as Maslach Burnout Inventory section on empathy and dehumanization, Jefferson Scale of Physician Empathy and the Perceived Stress Scale. Measures for disrespect and abuse were adapted from evaluations completed by Asefa et al (12), Population Council's HESHIMA project (13) and the Maternal and Child Health Integrated Program Respectful Maternity Care Indicator Compendium (14).

Hour-long surveys and interviews were conducted at the facilities at times when providers were not otherwise occupied with professional obligations. Surveys with providers solicited quantitative information on provider background, professional responsibilities, typical client behaviors and providers' responses to these behaviors, and elements of respectful care. Surveys were used to capture providers' perspectives on patient experience, levels of rapport, empathy and trust between providers and clients and to understand providers' perceptions of their role and disrespectful care. At endline, additional qualitative questions were added to the surveys to develop a more nuanced understanding of provider perceptions related to RMC as well as understand intervention facility providers' experience implementing the solution package. 
Safe Motherhood Action Group (SMAG) volunteers, community members who liaise between health facilities and clients in the community, helped our research team identify and make introductions to eligible clients. Eligible clients were invited to the health facility to participate in the hour-long surveys. Surveys with clients solicited quantitative information on participant background, the client birth experience, provider-client dynamics, and positive and negative elements of the birth experience. Additional qualitative questions were added to the surveys at endline to develop a more nuanced understanding of clients' experiences and to learn more about client interaction with the solution package. Qualitative interviews with supervisors concerned participant background, supervisory responsibilities, experience implementing the solution package and provider practices, and typical client behaviors.

We conducted multi-hour observations in the labor ward of the implementation facilities only. Observations were conducted when clients arrived at the labor and delivery ward, provided that clients and providers felt comfortable with our presence and gave informed consent. Observations were captured in an objective and detailed fashion: all conversations and interactions between clients and providers and any other parties present were recorded in detailed notes, as were providers' utilization of the solution package.

\section{Analysis}

Our theory of change was used to develop our analytic approach to assess the effectiveness of the RMC solution package and whether or not the solution package improved client experience of care during facility-based deliveries. Our primary outcomes outlined in the theory of change were assessed by whether (1) Provider has ever done anything that they consider to be disrespect and abuse towards a client in childbirth (2) The client experienced any instance of disrespect ${ }^{1}$ (3) The provider yelled or scolded the patient (4) Client rated care as very good or excellent and (5) The provider treated me [the client] well during labor and delivery

We estimated the effect of the solution package on the outcomes of interest using an ordinary least squares (OLS) regression to measure the differences in the outcome variables at endline between intervention and comparison groups. To isolate the estimated effect of the solution package, we controlled for facility-level baseline averages in all regressions, whether focusing on provider or client outcomes. In addition, we controlled for observed differences between intervention and comparison provider groups at baseline and other potential confounders. We adjusted for whether a provider was a midwife rather than a nurse or doctor, the provider's sex, years of experience in the delivery ward, and the number of deliveries attended within the last 2 weeks. In the client outcome-focused analyses, we adjusted for facility level baseline averages for each outcome of interest, as well as a client's marital status, age, and parity.

Because our research design did not include random assignment and, therefore, did not allow us to control for other factors that might influence both the intervention and comparison groups, we also conducted a difference-in-difference analysis to further validate the findings. This analysis explored whether outcomes in the intervention facilities were similar to what we may have expected if the intervention had not occurred. This approach assumes that intervention and comparison facilities have similar trends over time, which we could not validate due to limited data points. In instances where the difference-in-difference results did not confirm significant OLS regression findings, we believe the OLS regressions still suggest a meaningful effect, though the size of the effect may be less certain due to other factors not captured in the OLS regression. Quantitative data was analyzed using Stata/IC version 14.0 .

Qualitative data was also used to develop a more nuanced understanding of the results. In-depth interviews were conducted in Nyanja (dominant local language) and audio recorded and notes were transcribed directly into English. We employed thematic analysis, drawing from the process outlined by Braun and Clarke (15). An initial set of codes was drawn from the theory of change described above. Data were matched to each component of the theory of change, and four members of the research team individually assessed the extent to which the evidence supported or contradicted the pathway, or whether evidence was mixed using Microsoft Excel.

${ }^{1}$ Measures of disrespect included whether the provider made the client feel uncomfortable, shouted/scolded or said something harsh or unkind, threatened to withhold treatment, made threatening, negative or discouraging comments, ignored or abandoned client when in need, hit, slapped, pushed, pinched or otherwise beat the client, client delivered alone, client had surgery done without consenting, or client's body was seen by others or privacy was violated in another way.

\section{Results}

A total of 220 surveys of providers and clients were completed between baseline and endline ${ }^{2}$. Of those surveys, 33 providers were surveyed at baseline and 35 at endline. Of the providers surveyed at baseline, 22 were available to be surveyed at endline. 60 clients were surveyed at baseline and 92 at endline, each survey representing a unique individual. Five interviews were conducted with intervention facility in-charges and ten multi-hour observations were conducted at intervention facilities. A further breakdown of survey participants is found in Table 3 . 


\begin{tabular}{|lll|}
\hline & Baseline & Endline \\
\hline Provider Survey & & 22 \\
\hline Intervention & 18 & 13 \\
\hline Comparison & 15 & 35 \\
\hline Total & 33 & \\
\hline Client Survey & & 47 \\
\hline Intervention & 28 & 45 \\
\hline Comparison & 32 & 92 \\
\hline Total & 68 & \\
\hline Observation Visits & 10 multi-hour observations \\
\hline Interviews with facility in-charges & 5 interviews & \\
\hline Facility Administrative data & Data was reviewed for the October- December 2018 and October-December 2019 period \\
\hline
\end{tabular}

Table 4 shows the demographics of the providers and clients surveyed both at baseline and endline.

Table 4

Provider and Client demographics at baseline and endline, by intervention and comparison sites

\begin{tabular}{|c|c|c|c|c|c|c|}
\hline & \multicolumn{3}{|c|}{ Client Baseline } & \multicolumn{3}{|l|}{ Client Endline } \\
\hline & $\begin{array}{l}\text { Intervention } \\
(\mathrm{N}=\mathbf{2 8})\end{array}$ & $\begin{array}{l}\text { Comparison } \\
(\mathrm{N}=32)\end{array}$ & $\begin{array}{l}\text { Full } \\
(\mathrm{N}=60)\end{array}$ & $\begin{array}{l}\text { Intervention } \\
(\mathrm{N}=47)\end{array}$ & Comparison $(\mathrm{N}=45)$ & $\begin{array}{l}\text { Full } \\
(\mathrm{N}=92)\end{array}$ \\
\hline Age & 23.8 & 23.2 & 23.5 & 24.7 & 24.3 & 24.5 \\
\hline Parity & 2.4 & 2.6 & 2.5 & 2.4 & 2.3 & 2.4 \\
\hline Marital status & $\begin{array}{l}95 \% \\
\text { married }\end{array}$ & $\begin{array}{l}94 \% \\
\text { married }\end{array}$ & $95 \%$ married & $85 \%$ married & $73 \%$ married & $79 \%$ married \\
\hline \multirow{4}{*}{$\begin{array}{l}\text { Age of most recent child delivered, in } \\
\text { months }\end{array}$} & 1.1 & 1.0 & 1.0 & 1.1 & 1.1 & 1.1 \\
\hline & \multicolumn{3}{|c|}{ Provider Baseline } & \multicolumn{3}{|c|}{ Provider Endline } \\
\hline & Intervention & Comparison & Full & Intervention & Comparison & Full \\
\hline & $(\mathrm{N}=18)$ & $(\mathrm{N}=15)$ & $(\mathrm{N}=33)$ & $(\mathrm{N}=22)$ & $(\mathrm{N}=13)$ & $(\mathrm{N}=35)$ \\
\hline Age & 36 & 39 & 38 & 37 & 36 & 37 \\
\hline Percent Female & $100 \%$ & $67 \%$ & $85 \%$ & $86 \%$ & $62 \%$ & $77 \%$ \\
\hline Midwife & $56 \%$ & $53 \%$ & $55 \%$ & $55 \%$ & $54 \%$ & $54 \%$ \\
\hline Years of experience attending deliveries & 9.4 & 10.1 & 9.7 & 9.9 & 8.2 & 9.3 \\
\hline No. delivery in past 2-weeks & 3 & 3 & 3 & 2 & 2 & 2 \\
\hline
\end{tabular}

\section{Disrespect and Abuse}

To determine whether the solution package affected our primary outcome, clients experiencing fewer instances of disrespect, we relied on several indicators. We also measured changes in intermediate outcomes related to disrespect and abuse. To assess these outcomes, we measured whether the client experienced any instance of disrespect and abuse, if the provider self-reports use of behavior they would describe as disrespectful or abusive, and whether providers believes that colleagues believe that yelling at or scolding a patient is never acceptable.

OLS findings suggest that at endline, clients at implementation facilities were significantly less likely, 15 percentage points, to experience any form of disrespect and abuse (including lack of privacy, threats, delivering alone and abandoned, and being made to feel uncomfortable) compared to clients at 
comparison facilities $(B=-0.15 p=.01)$. The difference-in-difference analysis did not validate this finding $(B=0.05 p=0.61)$. (See Supplementary Table 1, Additional File 1).

There were no observed differences in whether providers witnessed their colleagues engaging in acts of disrespect and abuse between intervention and comparison facilities (See Supplementary Table 2, Additional File 1). At baseline, the percentage of providers who reported ever witnessing disrespectful care by colleagues was relatively high, with $72 \%$ of intervention providers and $81 \%$ of comparison providers reporting that they had ever witnessed disrespect and abuse by colleagues. At both baseline and endline, providers reported witnessing all four kinds of disrespect and abuse that we explored (use of force, threatening client, showing disrespect due to client attribute, and scolding), though scolding was the most commonly reported form. Despite high rates of witnessing disrespectful care, providers generally reported that their colleagues treated clients acceptably on a scale of totally unacceptable to perfectly acceptable.

A much smaller percentage of intervention and comparison providers reported that they themselves had treated clients disrespectfully, and there was no significant difference between intervention and comparison providers in self-reported acts of disrespect and abuse at endline (See Supplementary Table 3, Additional File 1).

Evidence on whether there was a change in provider's perception that yelling or scolding is never acceptable amongst colleagues was not clear. Findings from the OLS at endline, though not statistically significant, suggest that providers at the intervention facilities were more likely to state that providers at their facility believe that yelling at or scolding a patient is never acceptable compared to providers at comparison facilities $(B=.5, p=.09)($ See Supplementary Table 4, Additional File 1). Qualitatively a few providers remarked that if a client 'broke' the provider-client promise, then they were justified in scolding, therefore this result is not clear. The difference-in-difference analysis did not confirm the regression results $(B=.30, p=.21)$.

We also adapted the Maslach Burnout Inventory section on empathy and dehumanization ${ }^{3}$, to measure provider burnout and decipher whether it was linked to disrespectful care. Survey results found low levels of burnout at baseline across providers (mean values of 5 on a scale of $0-42$ ). We also found no correlation between provider burnout and self-reported instances of disrespectful care.

\section{Provision of Pain Management}

As per our theory of change, pain management support was an important intermediary to provision of better care. To identify whether the intervention impacted provision of pain management we considered several outcomes including frequency of use of pain management techniques as reported by providers, whether provider considers pain management support as one of the three most important tasks completed during labor and delivery, and whether the client reports requesting pain management support.

Clients were asked whether they requested help from the provider when they were feeling pain during labor and delivery. OLS results show that at endline, clients at intervention facilities were 33 percentage points more likely to request pain management compared to clients who delivered at comparison facilities ( $B=.33, p=.003$ ). $70 \%$ of clients at intervention facilities requested support compared to $36 \%$ of clients at comparison facilities at endline. The difference-in-difference analysis confirmed these results ( $(=.33, p=.04)$ (See Supplementary Table 5, Additional File 1 ).

We also asked providers to select the three most important tasks they do during delivery from a pre-determined list of common tasks observed in our formative research. At endline, though not statistically significant, OLS findings suggest that providers at intervention facilities were 29 percentage points more likely to rate pain management as one of the most important tasks during delivery compared to providers at comparison facilities ( $B=.29$, $p$ $=.06$ ). Moreover, $23 \%$ of providers at intervention facilities selected pain management as important, compared to $8 \%$ of comparison providers at endline. However, the difference-in-difference analysis did not confirm the results $(B=.16, p=.37$ ) (See Supplementary Table 6, Additional File 1). Nonetheless, qualitative findings suggest that the intervention had a meaningful effect. For instance, providers described how the solutions helped emphasize their responsibility to provide pain management. They also described how the provider-client promise served as another reminder of the importance of providing pain management.

Survey data did not indicate a significant change in the number of pain management techniques a provider could recall or used between intervention and comparison groups (See Supplementary Table 7, Additional File 1), but there was a positive trend in the use of more effective and technical pain management techniques amongst intervention providers. At baseline the most commonly cited techniques used by intervention providers when a client requested pain management were massage, encouragement and chat. At endline, the three most commonly applied techniques were massage, breathing exercises and change position, which were all techniques outlined in the BETTER pain management toolkit. Qualitatively, providers at intervention facilities also described the pain management toolkit as playing a role in expanding the types of pain management techniques used during labor:

"Before the orientation I would just tell the client to do breathing exercises that when she does breathing exercises and has enough oxygen, the pain will reduce, but after orientation if the client can't manage to do breathing exercises and has back pain I can use the ball to rub her back. So now we have a number of pain management techniques we are using to relieve the clients' pain."

Moreover, several clients reported the massage ball as something that they particularly enjoyed and something different from previous deliveries. One client from an intervention facility noted, "I loved the way they treated me and the use of a ball to rub my back, the way they used to talk to me when in pain, and the way they encouraged me." - Intervention Facility Client

Page $7 / 12$ 


\section{Agency to Improve Quality of Care}

The section below describes outcomes related to provider's agency to improve quality of care. As described in the theory of change, a mechanism for provision of better care was that "Provider reflects on the current state of care and intends to improve." To measure providers' agency, we measured providers' interest in improving care as well as perceived need for improvement.

Most providers, in both intervention and comparison facilities, reported that they were very or extremely interested in improving care at facilities at baseline; on a scale of $1-5,5$ being extremely interested, the average response at baseline across providers was 4.5 . Despite expressing interest in improving care, most providers at intervention and comparison facilities did not report a need to improve. When asked to describe the state of care of their facility, ranging from "the facility provides excellent care with little to improve" to "the facility does not provide good care and could improve in many areas," most providers across intervention and comparison facilities evaluated the state of care favorably with "facility provides good care with a few areas to improve." Providers, in both intervention and comparison facilities, generally reported feeling able to improve client experience during delivery with no significant differences between intervention and comparison at endline.

\section{Rapport, Empathy, and Trust between Provider and Patient}

The section below describes outcomes related to the intermediate outcome described in the theory of change, "Rapport, empathy and trust exists between provider and patient". Questions were asked of both providers and clients to measure this outcome including an index to measure provider empathy, whether a client reports trusting their provider, report that the provider cared for them and clients' belief that their satisfaction was important to the provider.

Empathy was measured through an index, based on responses to six different questions, including whether a provider reported "understand[ing] what is going on in my clients' minds by paying attention to their nonverbal cues and body language" or agreed that "my clients feel better when I understand their feelings," statements adapted from the Jefferson Scale of Physician Empathy (16). At endline, as measured on a scale of 0-5, though not statistically significant, findings suggested that providers in intervention facilities were more likely to be more empathetic towards clients $(B=.20$, $p=.07$ ) as compared to providers at comparison facilities. The results were, however, not corroborated by the difference-in-difference analysis $(B=.03, p=.83)$ (See Supplementary Table 8, Additional File 1).

At both baseline and endline, almost all clients reported trusting their provider, feeling that their provider cared for them, and believing that their satisfaction was important to providers. However, clients' qualitative reflections were mixed. Several clients described feeling a sense of relief at being promised the kind of care described in the provider-client promise, indicating that this kind of care was not necessarily what they had expected. Clients reported that they felt confident that the provider would follow their promise, and none reported feeling that the promise had been broken during her delivery. Clients also remarked that the promise was educational and that they valued being consulted and involved.

\section{Client Expectations and Satisfaction}

Below we describe findings from our primary outcome of interest, "Clients are more satisfied with care" as well as expectations of care, which was measured across several different aspects of care described below.

While clients reported being satisfied with care overall, clients' expectations for respectful care were low and did not increase during implementation. At baseline, across intervention and comparison facilities, almost half of clients said they expected that a provider would yell or scold them and a third said they expected the provider might use insults, intimidations, threats, or coercion. Several women explicitly mentioned that they expected to be shouted at or slapped either because they were arriving late to the facility or because this is what they had heard from others. These values remained high at endline; $40 \%$ of intervention and comparison clients expected their provider to yell or scold them during labor and delivery and $32 \%$ expected their provider might use insults, intimidations, threats or coercion.

Despite having an expectation of disrespectful care, almost all clients, across intervention and comparison facilities, also reported an expectation that providers would provide "good care" at baseline and values remained high at endline. Not being shouted at or beaten or having the provider's assistance with anything not immediately essential to a safe delivery (such as helping to clean up bodily fluids after delivery) were described as reasons to be particularly satisfied with the care received rather than examples of care one should expect.

Across intervention and comparison facilities, the endline qualitative findings suggest that women's low expectations of provider-client interpersonal care, may be linked to their focus on the baby's survival. Several women explained that they perceived a real risk that the baby might not survive, and allowed themselves to develop attachment to the baby only once they felt certain that the baby would live. Clients also mentioned that their primary concern during delivery was delivering a healthy baby, and our qualitative data suggested that even when clients expected disrespect and abuse, they reported being satisfied by the care they received if they delivered a healthy baby.

While our study did not detect a significant impact of the intervention on quantitative measures of client satisfaction or the importance of client satisfaction to providers, qualitative results suggest that both clients and providers at intervention facilities found utility in the feedback box. Providers described the feedback box as a means to understand client satisfaction; 
"For example, we are having unsatisfied clients, it will help us look into the matter and see where we are having the problem. If the clients are very satisfied and we have a lot of tokens then we know that we are doing our job and clients are appreciating if they are satisfied because of one or two things that they are not happy about, we try to talk among ourselves and try to solve the issue so that all the mothers can go home happy." Intervention Facility Provider

Clients from intervention facilities described "feeling good" about being asked to share their level of satisfaction through the feedback box. Additionally, clients commonly noted that they believed that positive feedback would be motivational for providers and that negative feedback would lead providers to change, thus suggesting their confidence in the feedback mechanism.

${ }^{2}$ We did not track the number of individuals who refused to participate.

${ }^{3}$ The Maslach Burnout Inventory is typically used to self-assess level of provider burnout. A subset of the questions was modified and adapted for use in our survey, specifically to measure burnout as it relates to dehumanization and empathy.

\section{Discussion}

This evaluation provides promising evidence of the potential for behaviorally-informed solutions to increase provision of RMC and the use of behavioral design to develop effective interventions. Our participatory design led to interventions which were feasible to implement without a significant investment of resources and were well-received by clients and providers. While we were unable to attribute the observed effects to particular components of the solution package, our results suggest that all but one of the five solutions, the fresh start funds, contributed meaningfully to these positive results. This aligns with the findings from our formative research phase, and highlights the value of the behavioral design approach which allowed us to identify a range of behavioral drivers impacting provision of RMC and established the need for a multi-faceted solution to address these challenges (5).

One specific finding from our formative research was that providers had a narrowly defined mental model of their role which focused on clinical tasks and avoiding client or infant death (5). One objective of the solutions was to expand the providers' mental model of their role to include pain management support as a means for improving client experience. The approach we employed was multi-faceted (role play with techniques, a manual, a reminder poster by the client bedside, a partograph guide by the provider's desk, and a massage ball) as research suggests that mental models are formed through repeated and continuous interaction (17). Through our design process, we were able to identify a range of contextualized touchpoints which could give providers repeated interaction with pain management cues. Our evaluation findings suggest that the interventions shifted provider perception of their role, as there was a significant increase in providers citing pain management as a priority task, and also that this mechanism contributed to improved pain management provision. These findings point to strengths in the behavioral design approach, both in identifying the appropriate behavioral mechanisms to target as well as choosing effective intervention points to activate these mechanisms. While our solutions were limited to those which could be deployed at the facility level, additional opportunities exist to reshape providers' mental model of their role through the addition of pain management content in midwifery school curriculum.

Client satisfaction was a key outcome of interest in our evaluation as were other intermediate outcomes related to client expectations of care. The challenges in accurately capturing client satisfaction are well-established in the literature $(18,19)$, and our results suggest that measures other than client satisfaction may be more appropriate for identifying opportunities for improvement which are aligned with client desires. Our evaluation findings, which align with findings from our formative research, suggest that reported satisfaction was linked to whether the highest priority of the client was met, rather than whether or not the experience was satisfactory across a range of components of interest. That is, clients' greatest concern was delivering a healthy baby and as long as that expectation was met, they also reported high levels of satisfaction and assessed "good care" and "trust" through this lens. Measurements of client satisfaction intend to capture opportunities for improvement, but since clients, in all service interactions, will assess satisfaction as related to expectations and pressing priorities, satisfaction as a means for assessing the match between desired experience and actual experience falls short. Measures should instead capture a range of different features clients deem important to their care experience since otherwise, one particularly weighty element (the infant's safety) may skew reported satisfaction and obscure opportunities for making care more respectful and responsive to client desires. Clear, specific measures of dimensions of client satisfaction may also facilitate providers' recognition of areas for improvement, since our findings also suggest that most providers are interested in improving care without feeling a strong reported need for improvement.

Our evaluation has a few potential limitations. First, it was not feasible to randomly assign facilities to intervention or comparison conditions, which makes it more challenging to distinguish between effects driven by the intervention and those due to differences between the intervention and comparison facilities and providers for which we were unable to adjust. Our regression analyses adjusted for differences that we were able to observe, and we conducted a difference-in-difference analysis to substantiate findings from our regression analysis, but it remains possible that unobserved differences in characteristics and trends between the two groups influenced our results and may also have contributed to instances where the OLS and difference-in-difference findings did not align. This may also suggest that the size of the effect found from the OLS regressions may be due in part to factors for which we were unable to control.

We used insights from qualitative interviews as appropriate to strengthen the analysis. Another limitation is that we were only able to conduct the evaluation in a small number of facilities for a short duration of just over two months and with a small sample. The short duration of the evaluation

Page 9/12 
may not fully capture the impact of the interventions implemented, and the small sample means there was less power to detect differences. Possibly because of the limited size of the sample, the difference-in-difference results did not always validate the OLS findings.

Another limitation of our findings relates to challenges in implementation of the interventions, particularly the reflection workshop. Provider participants changed between baseline and endline data collection rounds, and while materials were provided to orient providers to the solution package, it is not clear that providers who did not attend the workshop received the same intensity of the intervention which may also impact results and minimize observable impact of the intervention.

\section{Conclusions}

The results of this study demonstrate the potential impact of the solution package we developed and implemented to address drivers of disrespectful and abusive care during labor and delivery in Zambia. These results support the case for a larger scale evaluation to further validate the effectiveness of the solutions and identify the relative effects of the different components of the solution package. In other settings where providers face barriers to providing RMC similar to those identified in our formative research, an adaptation of this solution package might lead to similarly positive results. Given the global scale of the problem of disrespectful care, these low-cost solutions hold promise for improving the quality of care women receive during labor and delivery.

\section{List Of Abbreviations}

OLS Ordinary Least Squares regression

RMC Respectful Maternity Care

SM360+ Safe Motherhood 360+

SMAG Safe Motherhood Action Group

\section{Declarations}

\section{Ethics approval and consent to participate}

Our study was reviewed and approved and monitored by two institutional review boards, Advarra (US-based) (protocol number 28374) and ERES Converge (based locally in Zambia) (no protocol number). Participants provided informed written consent to participate.

\section{Consent to publish}

Not applicable.

\section{Availability of data and material}

The datasets used and/or analyzed during the current study are available from the corresponding author on reasonable request.

\section{Competing interests}

The authors declare that they have no competing interests.

\section{Funding}

Funding for the study was provided by the United States Agency for International Development (USAID) as part of the ongoing social and behavior change research and evaluation project, Breakthrough RESEARCH. Breakthrough RESEARCH is made possible by the generous support of the American people through the United States Agency for International Development (USAID) under the terms of cooperative agreement no AID-OAA-A-17-0018. The contents of this manuscript are the sole responsibility of the Breakthrough RESEARCH project and Population Council and do not necessarily reflect the views of USAID or the United States Government.

\section{Authors' contributions}

JS led solution design and testing, conceived of research questions, analyzed and interpreted data, and wrote manuscript sections. AS conceived of research questions, analyzed and interpreted data, and wrote manuscript sections. RB led solution design and testing, conceived of research questions, analyzed and interpreted data, and reviewed and refined the manuscript. AS conceived of research questions, developed the analysis strategy, analyzed and interpreted data, and reviewed and refined the manuscript. EZ reviewed and refined the manuscript. AK participated in solution design and testing, facilitated local research and implementation, and reviewed findings. All authors have read and approved this manuscript.

\section{Acknowledgements}


The study team would like to thank all those who facilitated and contributed to this research, including the Safe Motherhood $360+$ team, the Chipata District Health Office, the staff of the health facilities where research was undertaken, and the individual study participants.

\section{References}

1. Bohren MA, Mehrtash H, Fawole B, Maung TM, Balde MD, Maya E, et al. How women are treated during facility-based childbirth in four countries: a cross-sectional study with labour observations and community-based surveys. The Lancet. 2019 Nov 9;394(10210):1750-63.

2. Kujawski SA, Freedman LP, Ramsey K, Mbaruku G, Mbuyita S, Moyo W, et al. Community and health system intervention to reduce disrespect and abuse during childbirth in Tanga Region, Tanzania: A comparative before-and-after study. Tomlinson M, editor. PLOS Med. 2017 Jul 11;14(7):e1002341.

3. Ratcliffe HL, Sando D, Lyatuu GW, Emil F, Mwanyika-Sando M, Chalamilla G, et al. Mitigating disrespect and abuse during childbirth in Tanzania: an exploratory study of the effects of two facility-based interventions in a large public hospital. Reprod Health [Internet]. 2016 Dec [cited 2018 Apr 9];13(1). Available from: http://reproductive-health-journal.biomedcentral.com/articles/10.1186/s12978-016-0187-z

4. Abuya T, Ndwiga C, Ritter J, Kanya L, Bellows B, Binkin N, et al. The effect of a multi-component intervention on disrespect and abuse during childbirth in Kenya. BMC Pregnancy Childbirth [Internet]. 2015 Dec [cited 2018 Jun 20];15(1). Available from: http://bmcpregnancychildbirth.biomedcentral.com/articles/10.1186/s12884-015-0645-6

5. Smith J, Banay R, Zimmerman E, Caetano V, Musheke M, Kamanga A. Barriers to provision of respectful maternity care in Zambia: results from a qualitative study through the lens of behavioral science. BMC Pregnancy Childbirth. 2020 Jan 9;20(1):26.

6. Datta S, Mullainathan S. Behavioral Design: A New Approach to Development Policy. Rev Income Wealth. 2014 Mar;60(1):7-35.

7. Hartmann MA, Datta S, Banay RF, Caetano V, Floreak R, Appaiah P, et al. Designing a Pilot Study Protocol to Test a Male Alcohol Use and Intimate Partner Violence Reduction Intervention in India: Beautiful Home. Front Public Health [Internet]. 2018 [cited 2020 Jul 10];6. Available from: https://www.frontiersin.org/articles/10.3389/fpubh.2018.00218/full

8. Spring H, Datta S, Sapkota S. Using Behavioral Science to Design a Peer Comparison Intervention for Postabortion Family Planning in Nepal. Front Public Health [Internet]. 2016 Jun 21 [cited 2017 Jun 14];4. Available from: http://journal.frontiersin.org/Article/10.3389/fpubh.2016.00123/abstract

9. Buttenheim AM, Levy MZ, Castillo-Neyra R, McGuire M, Toledo Vizcarra AM, Mollesaca Riveros LM, et al. A behavioral design approach to improving a Chagas disease vector control campaign in Peru. BMC Public Health [Internet]. 2019 Sep 18 [cited 2020 Jul 10];19. Available from: https://www.ncbi.nlm.nih.gov/pmc/articles/PMC6751594/

10. Central Statistical Office (CSO). 2010 Census of Population and Housing: Eastern Province Analytical Report [Internet]. 2014. Available from: https://www.zamstats.gov.zm/phocadownload/2010_Census/2010_Census_Analytical_Reports/Eastern\%20Province\%20Analytical\%20Report\%20\%202010\%20Census.pdf

11. Kruk ME, Kujawski S, Mbaruku G, Ramsey K, Moyo W, Freedman LP. Disrespectful and abusive treatment during facility delivery in Tanzania: a facility and community survey. Health Policy Plan. 2018 Jan 1;33(1):e26-33.

12. Asefa, Anteneh, Delayehu Bekele, Alison Morgan, and Michelle Kermode. 2018. "Service Providers' Experiences of Disrespectful and Abusive Behavior towards Women during Facility Based Childbirth in Addis Ababa, Ethiopia." Reproductive Health 15(1): 4.

13. Population Council. 2014. "Heshima: Promoting Dignified and Respectful Care during Childbirth in Kenya. SERVICE PROVIDER INTERVIEW." https://www.popcouncil.org/uploads/pdfs/Heshima_Provider-Survey-Tool_Final.pdf.

14. Maternal and Child Health Integrated Program. 2013. Respectful Maternity Care Measurement Workshop Report. https://toolkits.knowledgesuccess.org/sites/default/files/rmc_measurement_workshop_report_0.pdf.

15. Braun V, Clarke V. Using thematic analysis in psychology. Qual Res Psychol. 2006 Jan;3(2):77-101.

16. Jefferson Scale of Empathy - Thomas Jefferson University [Internet]. [cited $2020 \mathrm{Jul}$ 24]. Available from: https://www.jefferson.edu/university/skmc/research/research-medical-education/jefferson-scale-of-empathy.html

17. Brewer WF, Nakamura GV. The nature and functions of schemas. Cent Study Read Tech Rep No 325 [Internet]. 1984 [cited 2017 Jun 14 ]; Available from: http://www.ideals.illinois.edu/bitstream/handle/2142/17542/ctrstreadtechrepv01984i00325_opt.pdf?s

18. Larson E, Sharma J, Bohren MA, Tunçalp Ö. When the patient is the expert: measuring patient experience and satisfaction with care. Bull World Health Organ. 2019 Aug 1;97(8):563-9.

19. Glick P. How reliable are surveys of client satisfaction with healthcare services? Evidence from matched facility and household data in Madagascar. Soc Sci Med. 2009 Jan 1;68(2):368-79.

\section{Figures}




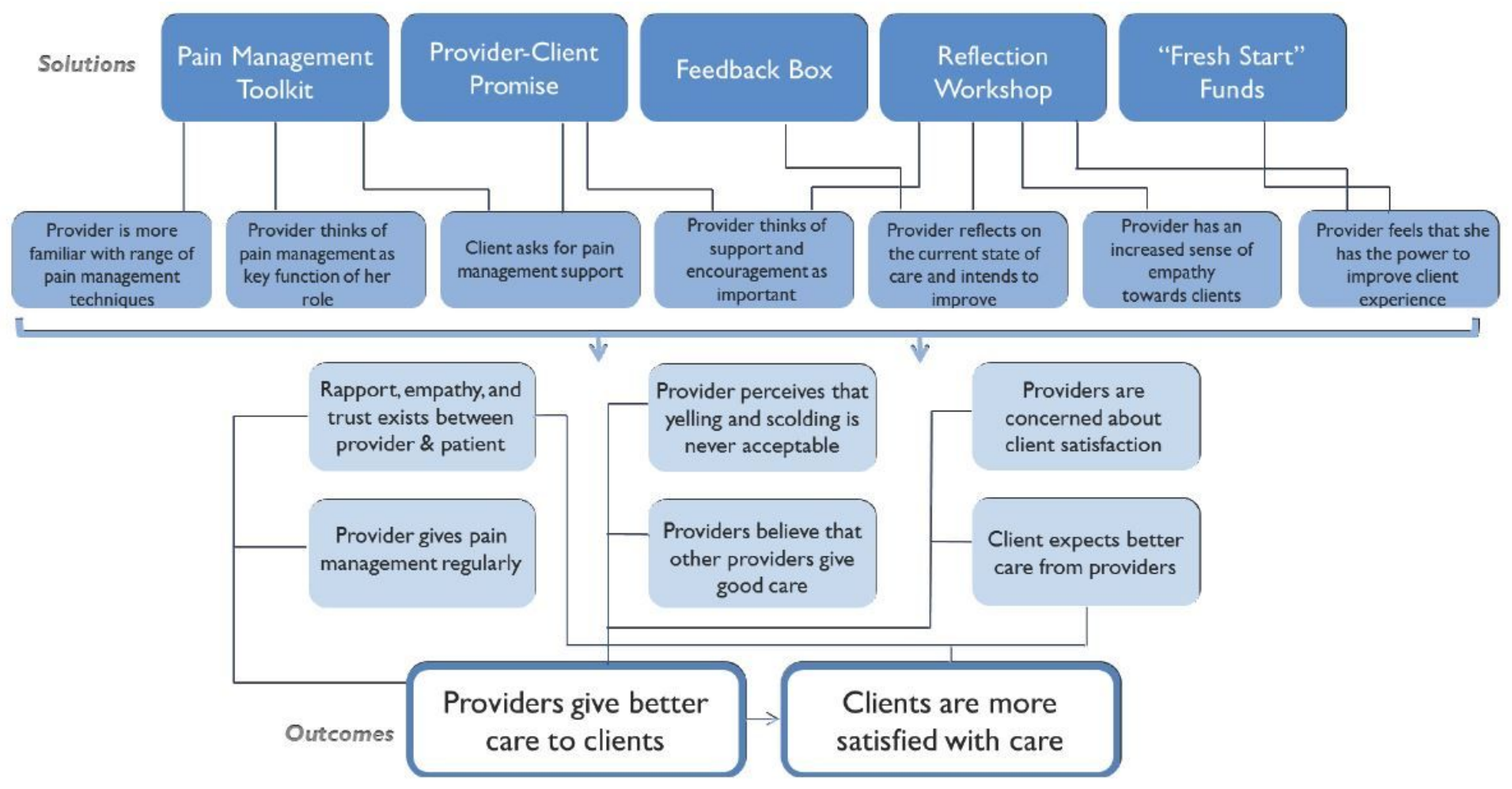

Figure 1

Theory of Change of the Intervention Package

\section{Supplementary Files}

This is a list of supplementary files associated with this preprint. Click to download.

- COREQRespectfulMaternityCare9.28.20.pdf

- AdditionalFile1.pdf

- AdditionalFile2instruments.pdf 